\section{Textbook of Surgery}

D. A. Macfarlane and L. P. Thomas. Pp. xi + 759, illustrated. Edinburgh and London: E. \& S Livingstone. 1964. 60s.

As stated by the authors in their preface, there is a constant demand from students for a good textbook of surgery at a reasonable price. This new text-book is an attempt by the authors, with the assistance of five other surgeons, to meet this demand. The book covers not only those aspects of surgery covered by the title "general surgery", but also orthopædics, thoracic surgery and neurosurgery. Each subject is dealt with in an essentially conventional manner, with an outline of the pathology of the condition in addition to its clinical features and treatment. There is also a brief review of the relevant physiology of the organ or system in question at the beginning of each chapter. In the interests of clarity and economy, the illustrations consist of line drawings.

The scope of the book is wide, and in each section the basic information is clearly set out, without undue attention to unimportant detail, though there are selected references at the end of each chapter for those who wish to pursue any subject further.

There is no doubt that this book should prove useful to the undergraduate, but in the process it may well bore rather than stimulate him. There is a curiously old-fashioned flavour about this book, despite the fact that it considers many of the most recent advances in surgery. This is partly due to the inadequacy of many of the line drawings, but more to the fact that in their attempt to achieve simplicity and brevity the authors seem to underestimate the ability of students to understand the problems of modern surgery. There is too much blurring of issues and the use of obscure terms (e.g. "stress" as an ætiological factor in duodenal ulcer) to make this an exciting book. As is inevitable in a book of this sort, any individual will find points of detail with which he disagrees, but it is a pity that on page 376 that there are two different descriptions of Duke's Classification of carcinoma of the rectum, one of which is wrong.

As a guide to the clinical aspects of surgery this book is very sound, and it is a pity that the more scientific aspects of the subject are not presented in a more precise and stimulating fashion.

\section{Progress in Medical Laboratory Technique-3}

Edited by F. J. BAKER. Pp. viii + 250, illustrated. London: Butterworths. 1964. 42s. 6d.

This third volume follows the pattern of its two predecessors, ranging widely in the field of laboratory technology and dealing with those innovations which have been adequately assessed and found to be of real advantage either in producing information not otherwise accessible or in producing it more economically. The articles in this volume maintain a very high standard, both in content and in mode of expression. Some indeed, are models for critical reviews and would dignify the pages of any scientific journal.

The initial article on steam sterilization reviews the practical problems of the autoclave in central sterile supply departments; the next five deal with histopathology, including new stains, freeze-drying, preparation for electron microscopy, and fluorescence techniques; this section ends with a most lucid account of recent developments in microscopes, covering image converters, polarizing microscopes, continuously variable magnification, fluorescent microscopy and the great variety of equipment now available for routine photomicrography. Sections on enzyme chemistry and thin layer chromatography are followed by a masterly review of the auto-immune diseases and very detailed expositions of the techniques required for their investigation.

There is no doubt that this series satisfies a need of pathologist and technician alike and is particularly important to those who work outside the great conurbations, for to them library visits require much valuable time and they may find it impracticable to conduct their own critique of methods.

\section{Tay-Sachs' Disease}

Edited by BRuno W. VolK, M.D. Pp. vii +158 , illustrated. New York and London: Grune and Stratton. 1964. \$5.75.

This monograph consists of five chapters, each of which is a masterly exposition on one aspect of Tay-Sachs' disease. The editor contributes two of the chapters, one being an historical review in which he points out that although Warren Tay (1881) was the first to describe the fundal appearance of the cherryred macula, it is to Bernard Sachs (1887) that priority should be given for the clinical and pathological features of the disease which he named "amaurotic familial idiocy".

The photographs of sections showing recent are superb. The chapter on biochemistry amply illusadvances in electron microscopy and histochemistry trates the recent dramatic advances, many made by the author, A. Saifer, particularly in our understanding of the metabolism of the gangliosides and the enzyme alterations which occur not only in patients but in their relatives. The final chapter on epidemiology fully discusses the genetic implications of why $80 \%$ of sufferers are Jewish.

All four contributors are associated with the special, if not unique, unit at the Jewish Chronic Disease Hospital in New York consisting of 17 beds set aside for the care and study of children with Tay-Sachs' disease and allied disorders.

Nearly 300 patients with this disease have been studied by the authors and their experience is not likely to be bettered.

Although occasional printing errors occur (e.g. Sherington, occular) this monograph is likely to remain the standard and definitive work on the subject.

\section{Control of Glycogen Metabolism}

Ciba Foundation Symposium. Edited by W. J. Whelan and Margaret P. Cameron. Pp. xiv + 434, illustrated. London: J. \& A. Churchill. 1964. $60 \mathrm{~s}$.

This is the report of a meeting held in July 1963 , with Professor F. G. Young as Chairman, and attended by many internationally distinguished con. tributors. The papers fall into two main groups. firstly, those concerned with glycogen metabolism and its normal regulation, and secondly, those describing studies of the different varieties of glycogen-storage diseases. The processes leading to glycogen synthesis 